\title{
Cost-Utility Analysis of a Medication Adherence Management Service Alongside a Cluster Randomized Control Trial in Community Pharmacy
}

\author{
Maria-Isabel Valverde-Merino (iD) \\ Fernando Martinez-Martinez (D) \\ Leticia Garcia-Mochon (iD) 2,3 \\ Shalom I Benrimoj (iD) ' \\ Amaia Malet-Larrea (iD) ${ }^{4}$ \\ Beatriz Perez-Escamilla (D) ${ }^{\prime}$ \\ Maria Jose Zarzuelo (D) \\ Andrea Torres-Robles (D) ${ }^{5}$ \\ Miguel Angel Gastelurrutia (D) \\ Raquel Varas-Doval (iD) ${ }^{6}$ \\ Tamara Peiro Zorrilla iD ${ }^{6}$ \\ Victoria Garcia-Cardenas (ID) \\ 'Pharmaceutical Care Research Group, \\ University of Granada, Granada, Spain; \\ ${ }^{2}$ Department of Management of Health \\ Services and Professionals, Andalusian \\ School of Public Health, Granada, Spain; \\ ${ }^{3}$ CIBER of Epidemiology and Public \\ Health (CIBERESP), Madrid, Spain; \\ ${ }^{4}$ Medicines Information Centre, Official \\ Pharmacist Association of Gipuzkoa, \\ Donostia/San Sebastian, Spain; ${ }^{5}$ Graduate \\ School of Health, University of \\ Technology Sydney, Sydney, Australia; \\ ${ }^{6}$ Pharmaceutical Care Services \\ Department, General Pharmaceutical \\ Council of Spain, Madrid, Spain
}

Background: It is necessary to determine the cost utility of adherence interventions in chronic diseases due to humanistic and economic burden of non-adherence.

Purpose: To evaluate, alongside a cluster-randomized controlled trial, the cost-utility of a pharmacist-led medication adherence management service (MAMS) compared with usual care in community pharmacies.

Materials and Methods: The trial was conducted over six months. Patients with treatments for hypertension, asthma or chronic obstructive pulmonary disease (COPD) were included. Patients in the intervention group (IG) received a MAMS based on a brief complex intervention, whilst patients in the control group (CG) received usual care. The cost-utility analysis adopted a health system perspective. Costs related to medications, healthcare resources and adherence intervention were included. The effectiveness was estimated as quality-adjusted life years (QALYs), using a multiple imputation missing data model. The incremental cost-utility ratio (ICUR) was calculated on the total sample of patients.

Results: A total of 1186 patients were enrolled (IG: 633; CG: 553). The total intervention cost was estimated to be $€ 27.33 \pm 0.43$ per patient for six months. There was no statistically significant difference in total cost of medications and healthcare resources per patient between IG and CG. The values of EQ-5D-5L at 6 months were significantly higher in the IG [IG: $0.881 \pm$ 0.005 vs CG: $0.833 \pm 0.006 ; p=0.000]$. In the base case, the service was more expensive and more effective than usual care, resulting in an ICUR of $€ 1,494.82 / Q A L Y$. In the complete case, the service resulted in an ICUR of $€ 2,086.30$ /QALY, positioned between the north-east and south-east quadrants of the cost-utility plane. Using a threshold value of $€ 20,000 / Q A L Y$ gained, there is a $99 \%$ probability that the intervention is cost-effective.

Conclusion: The medication adherence management service resulted in an improvement in the quality of life of the population with chronic disease, with similar costs compared to usual care. The service is cost-effective.

Keywords: chronic disease, medication adherence, health-related quality of life, cost-utility analysis, community pharmacy services, pharmacoeconomics

\section{Introduction}

Multi-morbidity in an aging population requires treatment with complex medication regimens leading to polypharmacy. ${ }^{1}$ Medications are one of the most frequently used and effective therapeutic tools to treat diseases. Patients' adherence to medication, a complex and multifactorial concept, is a key factor to achieve optimal benefits.

From the perspective of the patient and the healthcare system, non-adherence is a pressing worldwide health problem. The World Health Organization reported in
Correspondence: Maria-Isabel
Valverde-Merino
Pharmaceutical Care Research Group,
University of Granada Facultad de
Farmacia, Campus de Cartuja s/n,
Granada, I807I, Spain
Tel +34 958243827
Email misabelvalverdemerino@gmail.com 
2003 that approximately half of patients with chronic treatments are not adherent. ${ }^{2}$ Generally, it is estimated that $4 \%$ of patients do not initiate treatment, $30 \%$ are not adherent after 100 days, and 40\% discontinue medications after one year. ${ }^{3}$ Lack of medication adherence may lead to poor health outcomes and higher healthcare cost, due to additional physician visits, emergency care, hospitalizations and premature deaths. ${ }^{4,5}$ A systematic review identified the cost of non-adherence for different diseases, with values ranging from $\$ 949$ to $\$ 44,190$ per patient per year (values adjusted to 2015). ${ }^{6}$ Patients with chronic conditions, such as hypertension, asthma and chronic obstructive pulmonary disease (COPD), are particularly vulnerable to non-adherence behaviors, with estimated rates of $50 \%$ in patients suffering hypertension, ${ }^{7} 50-60 \%$ in asthma, ${ }^{8}$ and $70 \%$ in COPD. ${ }^{9}$ An inadequate management of these diseases may lead to an increased use of healthcare resources, with higher costs associated with $\mathrm{CV}$ events attributable to hypertension, ${ }^{10,11}$ poor asthma control $^{12,13}$ and COPD complications. ${ }^{13,14}$

Multi-component interventions ${ }^{15,16}$ have been proposed to improve adherence. A systematic review summarizing the evidence on the cost-effectiveness of adherence-enhancing interventions found that, although most interventions were cost-effective or cost-saving, variation existed with intervention types. ${ }^{17}$ In 2020, a Cochrane review concluded that welldesigned randomized controlled trials were needed to investigate the effects of interventions for improving medicationtaking ability and medication adherence in older adults who were prescribed multiple medications. ${ }^{18}$ At an international level, there is extensive evidence supporting the role of pharmacists in adherence management ${ }^{19-29}$ and several programs have eventuated from research. These adherence programs, implemented in several countries, vary in approach and population. For example, the Interdisciplinary Medication Adherence Program in Switzerland, ${ }^{30}$ the Cardiovascular medication non-Adherence Tailored Intervention (CATI) ${ }^{31,32}$ and the Medication Monitoring and Optimization (MeMO) in the Netherlands, ${ }^{33,34}$ the Italian medicines use review (I-MUR) for asthma patients, ${ }^{35}$ or the New Medicine Service (NMS) ${ }^{36-38}$ and the Pharmacy Care Plan (PCP) ${ }^{39}$ in England. However, the existing literature on economic evaluations is limited and with none being found in the Spanish community pharmacy setting.

In Spain, adherence management is identified as a national priority and has been included in a portfolio of Professional Pharmacy Services. ${ }^{40}$ A randomized controlled trial in 2017-2018, AdherenciaMED, ${ }^{41}$ evaluated in community pharmacy the impact of a novel Medication Adherence Management Service. The service was delivered by community pharmacists trained in a multicomponent intervention based on behavior change models and supported for a practice change facilitator. Patients were followed for six months. Effectiveness at improving medication adherence and clinical outcomes had been reported. ${ }^{42}$ The objective of this study was to evaluate the cost-utility of the pharmacist-led Medication Adherence Management Service (MAMS) compared with usual care, in patients with treatment for chronic conditions (hypertension, asthma or COPD). This paper reports on the total sample of patients.

\section{Materials and Methods}

The study followed the Consolidated Health Economic Evaluation Reporting Standards (CHEERS) guidelines for economic evaluations ${ }^{43}$ (Supplementary Information).

\section{Economic Evaluation Description}

A cost-utility analysis from a healthcare system perspective was undertaken with the objective of evaluating the cost-effictiveness of the MAMS performed by the intervention group (IG) compared to usual care in the control group $(\mathrm{CG})$. All costs were measured in euros $(€)$ updated to $2018^{44}$ and effectiveness was estimated in qualityadjusted life years (QALYs). No discount rate was applied for costs as the study's temporal horizon was less than one year (Table 1).

\section{Study Design and Characteristics}

The AdherenciaMED study ${ }^{41}$ was designed as a cluster randomized controlled trial (cRCT), in which community pharmacies were the unit of randomization. It was conducted in six Spanish provinces from October 2017 to April 2018. The target population were patients with pharmacological treatment for one of the three chronic conditions, hypertension, asthma or COPD. All the patients were provided a patient information sheet and signed an informed consent before inclusion. Patients attended six face-to-face monthly visits in the pharmacy's counselling area. More details of study design and characteristics of this cRCT are described in a previous article. ${ }^{42}$

\section{Intervention Group: Medication Adherence Management Service (MAMS)}

Patients in the IG received a community pharmacist-led Medication Adherence Management Service (MAMS, the 
Table I Components of the Economic Evaluation of the Medication Adherence Management Service

\begin{tabular}{|l|l|}
\hline Components & Cost-Utility Analysis \\
\hline Intervention & Medication Adherence Management Service (Intervention group, IG) \\
\hline Comparator & Usual Care (Control group, CG) \\
\hline Outcomes & $\begin{array}{l}\text { Medication prescribed cost } \\
\text { Healthcare resources cost } \\
\text { Intervention cost } \\
\text { Quality-adjusted life years (QALYs) }\end{array}$ \\
\hline Perspective & National Health System \\
\hline Time horizon & 6 months \\
\hline Software & $\begin{array}{l}\text { Microsoft Excel } \\
\text { STATA I5 }\end{array}$ \\
\hline
\end{tabular}

Abbreviations: CG, control group; IG, intervention group; QALY, quality-adjusted life years.

Service), a tailored service to identify and address adherence or non-adherence, with the aim of improving, maintaining or reinforcing medication adherence. The service consisted of a brief complex intervention based on a combination of multicomponent strategies (behavioral change models, educational, technical) which was personalized according to the characteristics and needs of each patient. The intervention was delivered following a sixstep protocol in monthly face-to-face consultations (Figure 1). All data were recorded by the pharmacist in an intervention electronic Data Collection Platform (eDCP), which guided the consultation. The pharmacist 's fidelity to the intervention protocol was monitored by a practice change facilitator (PCF) ${ }^{45-47}$ during their support visits. Full details of the intervention can be found in a published article. ${ }^{42}$

\section{Control Group: Usual Care}

Patients attending CG community pharmacies received usual care and completed a total of six visits, in which the pharmacist registered in the control eDCP for control pharmacies the sociodemographic data and other variables defined for this group of patients.

\section{Ethics}

The study was approved by the Research Ethics Committee of Granada and the Ethics Committee of University of Granada (358/CEIH/2017). The trial registration number on ANZCTR was ACTRN12618000410257.

\section{Costs}

The subcomponents of cost included in the analysis were:

\section{Prescribed Medication Cost}

Medication prescribed was recorded by the pharmacist for both IG and CG from electronic records and the patient's self-report. Only the prescribed medication related to the study diseases were considered in the analysis. These were identified using the Anatomical Therapeutic Chemical classification system (ATC groups C02, C03, C07, C08, C09, R03). ${ }^{48}$

Medication cost was calculated using the official list of drug prices in April 2018, ${ }^{49}$ taking into account the contribution of the national health system and excluding patient contributions. At baseline, the 1-month medication cost was collected, while at the end of the study, the sum of the monthly costs during the six months of follow-up was calculated.

\section{Healthcare Resources Cost}

Data related to visits to health professionals (primary care physician, specialist physician, emergencies and hospital admissions) in the previous six months were self-reported by patients of both IG and CG. This information was collected at the baseline and at the end of the six-month follow-up.

The cost of the visits to primary care physicians, specialist physicians and emergency department were calculated using prices from each of the autonomous community [comunidad autónoma ${ }^{50}$ ] public health systems, ${ }^{51-54}$ as prices per resource varied between different provinces. The hospital admissions cost was calculated using cost from the public system for diagnosis-related groups. $^{55}$ 


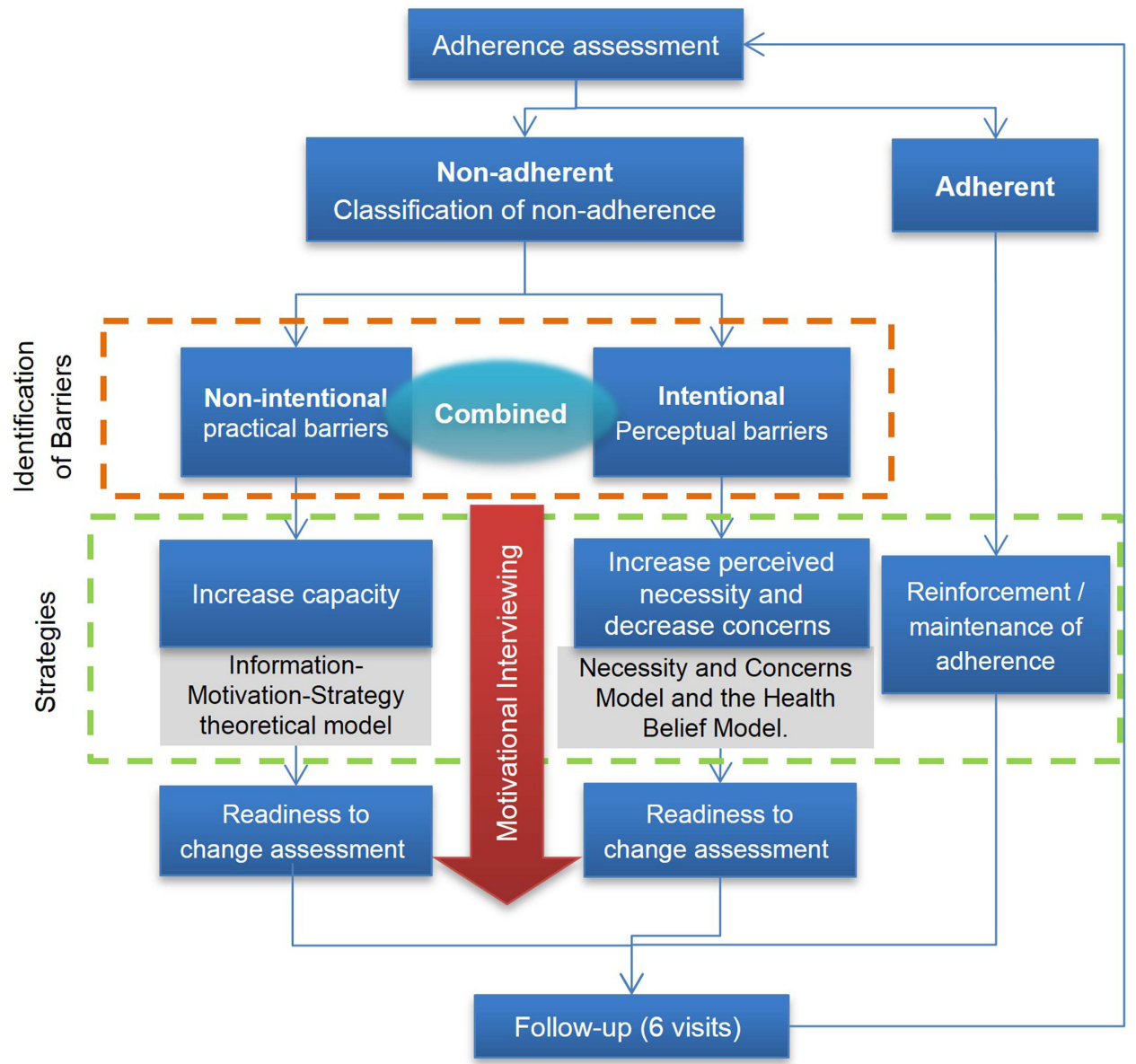

Figure I Medication Adherence Management Service intervention overview.

\section{Intervention Cost}

Cost related to the provision of the service was considered as the time employed by the pharmacist in the activities related to the MAMS. The IG pharmacists recorded the time employed in each visit with the patients, which including time taken for the patient's interview time and data collection. The mean time per patient for the six months for each pharmacist was calculated. Using the salary in the Spanish community pharmacy agreement, ${ }^{56}$ the estimated labor rate used was $€ 0.239 / \mathrm{min}$.

The pharmacy cost (investment and maintenance), training and facilitation to support the service were included in the IG arm. Firstly, the costs of the resources required to deliver the MAMS in the community pharmacies and maintenance costs over the time were included. This information was obtained from a previously published Spanish project, related to the cost of implementation of a pharmaceutical service. ${ }^{57}$ The investment cost included the patient counselling area, equipment and bibliographic resources. Maintenance cost included rent for the counselling area, utilities, equipment materials and subscriptions. General expenses and marketing were also included. These data were adjusted by the length of this study. Secondly, training cost for each pharmacist in IG was calculated by multiplying the estimated cost of labor rate of a provider pharmacist by total training time. And thirdly, the cost of the pharmacist's time spent during the visits with the PCF over six months was assessed. The cost of support visits to the pharmacy by PCF were calculated using the duration of visits and the estimated cost of labor rate.

The total number of potential patients who could benefit from the adherence service was estimated, based on the population per pharmacy ratio, the prevalence of study diseases in Spain and the estimated prevalence of nonadherence. It resulted in a potential number of 375 patients per pharmacy for 6 months. Using the total time employed by a provider pharmacist and the estimated potential number of 375 patients, the mean cost "per patient" was estimated for pharmacy, training and facilitation. 


\section{Utility from the Health-Related Quality of Life (HR-QoL)}

The HRQoL was measured with the Spanish version of EuroQol-5D-5L (EQ-5D-5L), ${ }^{58}$ which was completed by patients of IG and CG at baseline, three and six months. Utility was estimated using the published Spanish tariff. ${ }^{59}$ QALYs were calculated as the area under the curve. ${ }^{60}$

For missing data for the EQ-5D-5L data at three and six months, a multiple imputation with chained equations was used in order to allocate data at the different times of the study (baseline, 3 and 6 months). The multiple imputation missing data model included as predictive variables EQ-5D-5L indices at baseline and follow-up, province and study disease. Firstly, the missing data were imputed under the missing at random (MAR) assumption, the main analysis (base case). Secondly, completed case analysis was performed corresponding to a scenario where patients who completed all follow-ups can be considered representative of all the sample who initially agreed to participate, assuming data are missing completely at random (MCAR). The utilities shown in both cases have been adjusted for sex, province and disease. A simple pattern mixture model was implemented, following the approach recommended by Faria et al. ${ }^{61}$

\section{Cost-Utility Analysis}

The results of cost-utility analysis were presented as the Incremental Cost-Utility Ratio (ICUR). Incremental cost and QALYs were calculated using bivariate regression. QALYs were adjusted for baseline EQ-5D-5L to account for differences between groups at baseline. Costs were adjusted for baseline cost, gender, province and study disease. Coefficients were combined across the multiple imputed datasets using Rubin's rules. ${ }^{61}$ The probability that the intervention was cost-effective was calculated assuming the data were bivariate normal distributed. ${ }^{62}$ In order to analyze the uncertainty of the ICUR, a probabilistic analysis was performed with 1000 bootstrap replications. The result was expressed in a cost-effectiveness plane and an acceptability curve. A cost-effectiveness threshold, suggested for the Spanish population, of $€ 20,000 /$ QALY was included. ${ }^{63}$

To assess the robustness of the results, analyses of different scenarios were performed, alongside the missing data models previously described. The first model (base case) uses multiple imputation assuming missing data are MAR. In the second model (complete case) all the patients who did not return a HRQoL questionnaire were removed (assuming missing data are MCAR).

\section{Statistical Analysis}

Descriptive statistics were performed. Continuous variables were described by using mean and standard error (SE). Categorical variables were described as counts and percentages. Comparison of continuous variables between groups was undertaken using T-Student test (two groups of community pharmacies). Comparison of categorical variables was undertaken using $\chi 2$ tests or Fisher's exact test or Yates' chi-squared test when required. Significance was set at $\mathrm{p}<0.05$.

The data recorded in the eDCP by the pharmacists were extracted in Excel format. The analyses were performed using STATA 15.

\section{Results}

\section{Participants}

Ninety-eight community pharmacies and 138 pharmacists participated in the study. Initially, 1186 patients were recruited (CG: 553; IG: 633), with 148 patients lost to follow-up and 1038 patients (CG: 482; IG: 556) finishing the study.

Both study patient groups had similar characteristics at baseline, with a mean age of 64 years and 52.8\% being female. The proportion of enrolled patients was higher for patients suffering from hypertension (CG: 219, 39.6\%; IG: 283, 44.7\%) and lower from COPD (CG: 154, 27.8\%; IG: 145, 22.9\%). There were no statistical differences in the mean number of medications used between IG and CG at baseline. There were differences in the use of healthcare resources with the number of visits to primary care physicians, specialist physicians and hospital admissions, being significantly higher in the CG (Table 2).

\section{Costs}

\section{Prescribed Medication and Healthcare Resources Cost}

There were no baseline differences in the medication and healthcare resources related costs between IG and CG [IG: $72.85 \pm 32.06$; CG: $124.00 \pm 30.06 ; p=0.447]$. At the end of the study, the IG showed higher medication costs [IG: $228.35 \pm 11.98$; CG: $209.52 \pm 10.22 ; p=0.239$ ] and lower healthcare resources related costs; however, these differences were not statistically significant (Table 3 ). 
Table 2 Characteristics of Participants at Baseline ( $\mathrm{N}=1 \mid 86)$

\begin{tabular}{|c|c|c|c|}
\hline & Intervention Group $(n=633)$ & Control Group $(n=553)$ & p value \\
\hline Age; mean $\pm \mathrm{SE}$ & $64.0 \pm 15.6$ & $64.0 \pm 15.4$ & $1.000^{\mathrm{a}}$ \\
\hline Gender (female); n (\%) & $330(52.1)$ & $296(53.5)$ & $0.673^{\mathrm{a}}$ \\
\hline \multicolumn{4}{|l|}{ Education level; $n$ (\%) } \\
\hline $\begin{array}{l}\text { - No formal education } \\
\text { - Primary education } \\
\text { - Secondary education } \\
\text { - Higher non-university education } \\
\text { - University education }\end{array}$ & $\begin{array}{l}146(23.1) \\
258(40.8) \\
151(23.9) \\
9(1.4) \\
69(10.9)\end{array}$ & $\begin{array}{l}129(23.3) \\
201(36.3) \\
125(22.6) \\
13(2.4) \\
85(15.4)\end{array}$ & $0.47 I^{b}$ \\
\hline \multicolumn{4}{|l|}{ Employment situation; n (\%) } \\
\hline $\begin{array}{l}\text { - Student } \\
\text { - Unemployed } \\
\text { - Active worker } \\
\text { - Sick leave } \\
\text { - Retired }\end{array}$ & $\begin{aligned} 38 & (6.0) \\
62 & (9.8) \\
138 & (21.8) \\
21 & (3.3) \\
374 & (59.1)\end{aligned}$ & $\begin{aligned} 32 & (5.8) \\
51 & (9.2) \\
137 & (24.8) \\
13 & (2.4) \\
320 & (57.9)\end{aligned}$ & $0.685^{\mathrm{b}}$ \\
\hline \multicolumn{4}{|l|}{ Medications; mean \pm SE } \\
\hline $\begin{array}{l}\text { - Total medications } \\
\text { - Medications for the study disease }\end{array}$ & $\begin{array}{l}5.68 \pm 3.33 \\
1.82 \pm 0.93\end{array}$ & $\begin{array}{l}5.71 \pm 3.49 \\
1.75 \pm 0.87\end{array}$ & $\begin{array}{l}0.901^{\mathrm{a}} \\
0.196^{\mathrm{a}}\end{array}$ \\
\hline \multicolumn{4}{|l|}{ Healthcare resources; n (\%) } \\
\hline $\begin{array}{l}\text { - Primary care physician visits } \\
\text { - Specialist physician visits } \\
\text { - Emergency department visits } \\
\text { - Hospital admissions }\end{array}$ & $\begin{array}{l}135(2 \mid .3) \\
37(5.8) \\
16(2.5) \\
4(0.6)\end{array}$ & $\begin{array}{l}146(26.4) \\
49(8.9) \\
14(2.5) \\
12(2.1)\end{array}$ & $\begin{array}{l}0.040^{\mathrm{a}} \\
0.046^{\mathrm{a}} \\
0.997^{\mathrm{a}} \\
0.020^{\mathrm{a}}\end{array}$ \\
\hline \multicolumn{4}{|l|}{ Health Related Life Quality; mean \pm SE } \\
\hline $\begin{array}{l}\text { - Utility score } \\
\text { - VAS score }\end{array}$ & $\begin{array}{l}0.82 \pm 0.006 \\
68.54 \pm 0.70\end{array}$ & $\begin{array}{l}0.80 \pm 0.008 \\
67.90 \pm 0.81\end{array}$ & $\begin{array}{l}0.046^{\mathrm{a}} \\
0.540^{\mathrm{a}}\end{array}$ \\
\hline
\end{tabular}

Notes: Statistical tests: ${ }^{\mathrm{a}}$ t-test; ${ }^{\mathrm{b}}$ Fisher's exact test.

Abbreviations: SE, standard error; VAS, visual analog scale.

\section{Intervention Cost}

The mean time employed by the pharmacist per patient for the provision of MAMS in the IG was $116.28 \pm 42.13$ minutes during the 6 months of study (19.38 min per patient per month). This involved a cost of $€ 24.92 \pm 0.43$ per patient for the total six months.

Pharmacy costs based on a Spanish publication were reported to be $€ 2,138.27$ for the initial investment amortized over 5 years and $€ 783.66$ for annual maintenance. ${ }^{57}$ After adjusting this data to the study period and assigning the cost to each potential patient, it resulted in $€ 0.57$ as an initial investment and $€ 1.04$ for maintenance per patient for 6 months.

There were 74 pharmacists assigned to the IG. Each pharmacist received initially a 2 -day, 10 -hour training. Based on the estimated cost of the pharmacist's time and after assigning the cost to each potential patient, the cost of initial training resulted in $€ 0.38$ per patient.

Finally, the time spent during the visits of the practice change facilitator to the participant pharmacies was a mean of 11 hours per pharmacy. Based on the estimated cost of the pharmacist's time and assigning the cost to each potential patient, it resulted in $€ 0.42$ per patient for the total six months.

At the end of the study, the total cost associated with the MAMS was $€ 27.33$ per patient for six months (Table 3).

\section{Utility from the Health-Related Quality of Life (HR-QoL)}

Two alternative analyses, using the data obtained through the EQ-5D-5L scores at three study points (baseline, 3 and 
Table 3 Medication, Healthcare Resources and Intervention Cost [€] per Patient, Baseline and in Six Months Follow-Up [Mean (SE)] $(\mathrm{N}=1186)$

\begin{tabular}{|c|c|c|c|}
\hline & Intervention Group $(n=633)$ & Control Group $(n=553)$ & $\mathbf{P}$ value \\
\hline \multicolumn{4}{|l|}{ - Baseline Cost (previous 6 months, except*) } \\
\hline Prescribed medication (*previous month) & $35.46(1.86)$ & $33.55(1.63)$ & 0.447 \\
\hline Primary care physician visit & $13.36(1.23)$ & $16.57(1.25)$ & 0.069 \\
\hline Specialist physician visit & $6.09(1.03)$ & $9.27(1.37)$ & 0.062 \\
\hline Emergency department & $7.33(1.99)$ & $6.42(1.82)$ & 0.739 \\
\hline Hospital admissions & $46.06(31.95)$ & $91.28(29.52)$ & 0.300 \\
\hline Total baseline cost & $72.85(32.06)$ & $124.00(30.06)$ & 0.447 \\
\hline \multicolumn{4}{|c|}{ - Medication and healthcare resources cost (sum of 6 months follow-up) } \\
\hline Prescribed medication & $228.35(11.98)$ & $209.52(10.22)$ & 0.239 \\
\hline Primary care physician visit & $19.99(2.23)$ & $23.5 I(2.39)$ & 0.283 \\
\hline Specialist physicians visit & $6.50(1.97)$ & $6.57(1.40)$ & 0.978 \\
\hline Emergency department & $6.69(1.93)$ & |2.0| (2.84) & 0.114 \\
\hline Hospital admissions & $42.07(17.96)$ & $64.85(21.02)$ & 0.407 \\
\hline Total cost in six months follow-up unadjusted & $321.80(21.24)$ & $323.79(24.07)$ & 0.239 \\
\hline \multicolumn{4}{|l|}{ - Intervention cost (6 months follow-up) } \\
\hline Time of providing service & $24.92(0.43)$ & - & \\
\hline Initial investment in pharmacy & 0.57 & - & \\
\hline Annual maintenance of service & 1.04 & - & \\
\hline Initial training of pharmacist & 0.38 & - & \\
\hline Visits of practice change facilitator to pharmacy & 0.42 & - & \\
\hline Total intervention cost & $27.33(0.43)$ & - & \\
\hline
\end{tabular}

Notes: *It should be noted that the cost of prescribed medication only corresponds to one month in the baseline, while at the end of the study the sum of cost of six months were included. Statistical tests: $t$-test.

6 months), were considered, which differed in the way missing data was treated (Table 4).

There were no statistical differences at baseline in mean EQ-5D-5L scores from both groups [IG: $0.824 \pm$ 0.008 ; CG: $0.811 \pm 0.008 ; p=0.177]$. During the followup, patients in both groups perceived an improvement in their health-related quality of life, however the increase was greater in the IG [difference intragroup between baseline and month 6: IG: 0.06 vs CG: 0.03]. In the intergroup comparison, statistically significant differences were observed after the third month of the study with these remaining to the end of the study $(p=0.000)$.

\section{Cost-Utility Analysis}

Two models were considered in the cost-utility analysis (Table 5). In the first model (base case), the total mean cost was higher for the IG compared to the CG [IG: €371.93; CG: $€ 355.04]$, while the mean incremental QALY between both groups was 0.011 , resulting in an ICUR of $€ 1,494.82$ /
QALY. In the second model (complete case), the estimated ICUR was higher than in the base case ( $€ 2,086.30$ /QALY) because of a higher cost difference of $€ 21.68$ and a QALY difference of 0.010 between both groups CG and IG.

The graphical representation of the complete case model, based on 1000 bootstrapped replications, showed that in the cost-effectiveness plane most of the simulations were distributed in the upper-right quadrant and the lowerright quadrant, where the most expensive and most effective health technologies are found (Figure 2).

The acceptability curve shows that, using a threshold value of $€ 20,000$ for each QALY gained, there is a $99 \%$ probability that the intervention is cost-effective for the sample in the two models (with multiple imputation and complete cases) (Figure 3).

\section{Discussion}

This study measured the value of a community pharmacy intervention as a key element of the management 

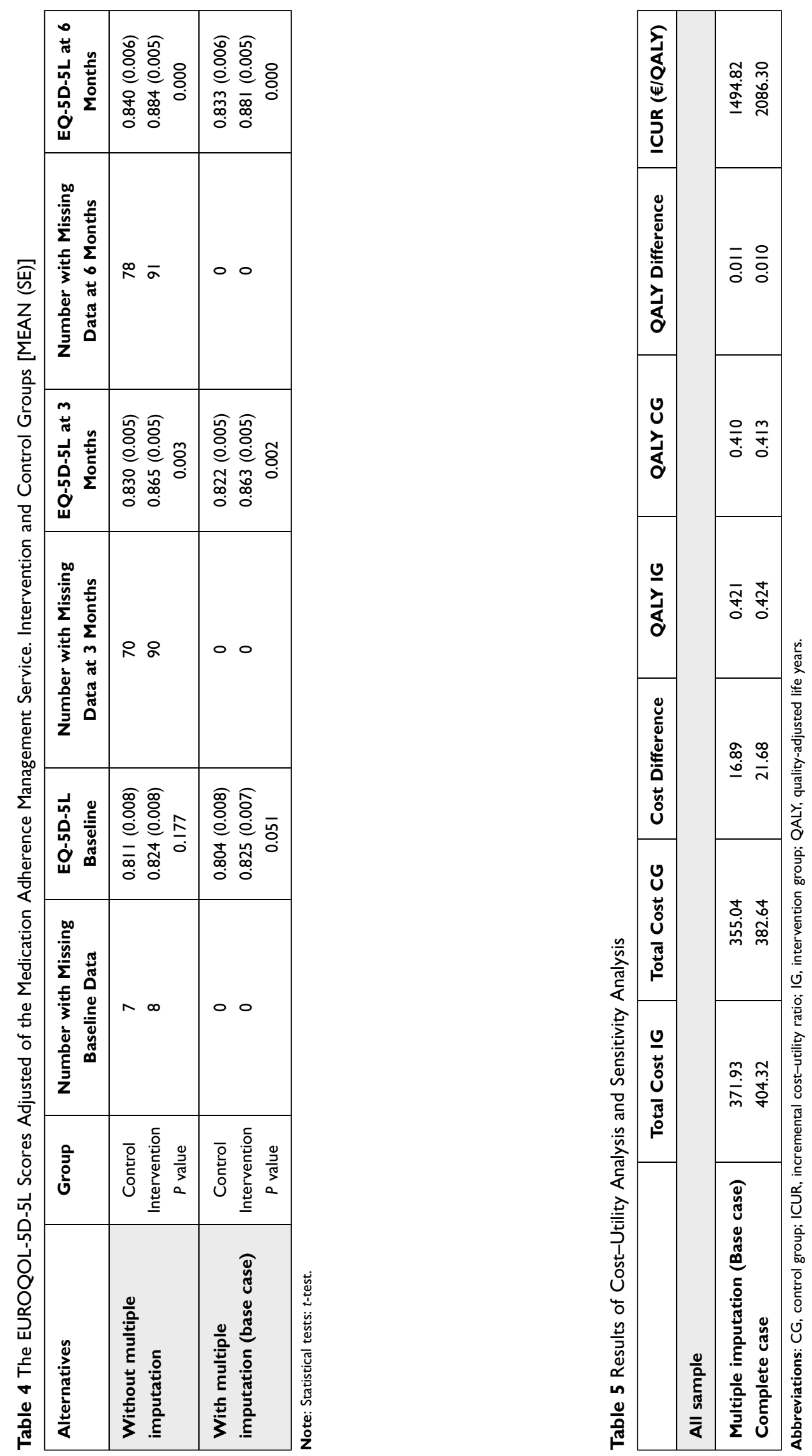


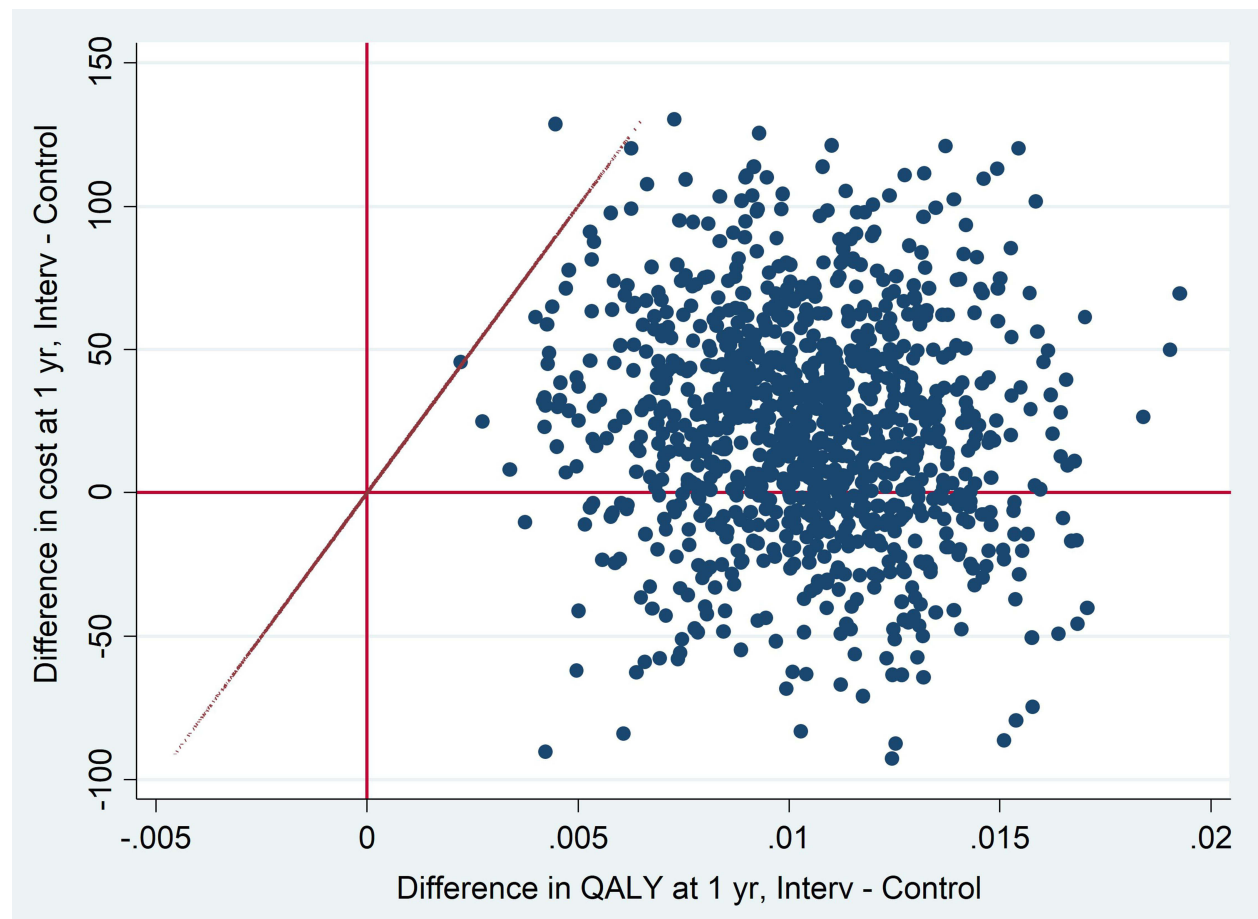

Figure 2 Cost-effectiveness plane for 1000 bootstrapped (complete case).

Abbreviations: Interv, intervention group; Control, control group; QALY, quality-adjusted life years; Yr, year.

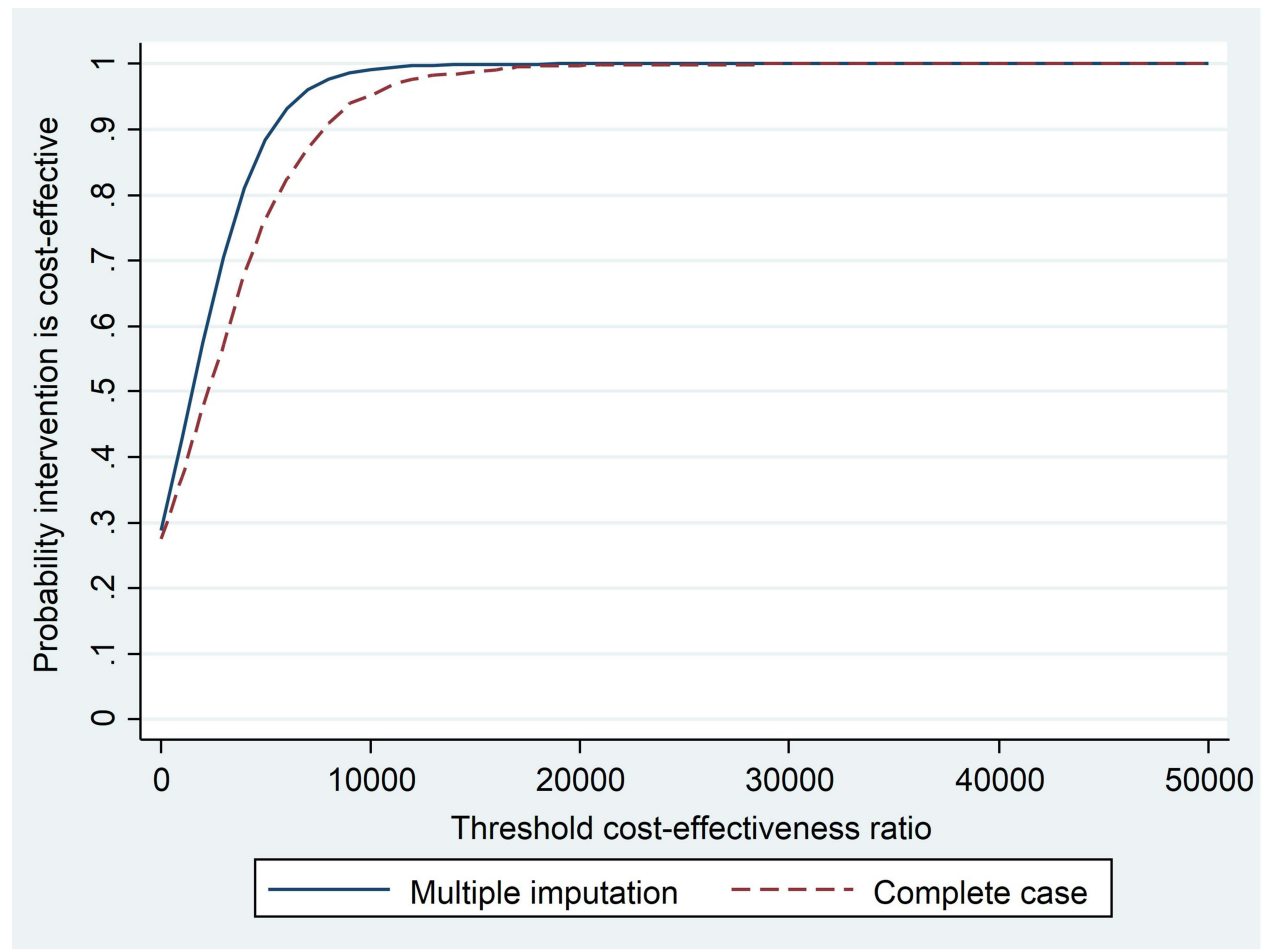

Figure 3 Cost-effectiveness acceptability curve for Medication Adherence Management Service.

of adherence for patients with chronic diseases, suggesting its value within primary care and the national health system. ${ }^{64-67}$ The present study adds to the evidence on economic evaluations of adherence programs in pharmacy, and fills the gap for Spanish community pharmacy. 
The results of the study provided evidence that the pharmacist-led Medication Adherence Management Service significantly improved the quality of life of the population with chronic disease with a non-significant difference in costs between intervention and control groups. This study reported an analysis of costs and described those related to the components of intervention cost.

An increase, although not significant, in the medication-related cost in the intervention group compared with the control group after 6 months follow-up was found. This may be indicative of the success of the service, since the intervention facilitates the process of using medications, and encouraging the patient to take in a correct manner their medication. These findings are supported by van Boven in two studies for patients with COPD, ${ }^{34,68}$ who reported an increase in medication costs associated with a greater adherence after the pharmaceutical intervention, while other studies the opposite effect was found. ${ }^{32,69,70}$ For example, Khdour et al69 reported that the costs of oral steroid and antibiotic courses were reduced in the intervention group in an intervention directed to increase adherence due to the decrease in exacerbations.

No significant difference was found in the cost of healthcare resources, such as self-reported visits to the primary care physician, specialist physician, emergency visits and hospital admissions. A small non-significant reduction was observed in all these variables in the intervention group. Other authors ${ }^{34,37,69,71}$ have found similar results, although the components used to estimate these costs do vary between studies. Similarly in other studies, ${ }^{34,68-70}$ the greatest reduction in costs was mainly associated with the decrease in hospital resources. These results however contrast with those described in two other programs, ${ }^{32,39}$ which reported a non-significant increase in costs associated with the use of healthcare resources after the intervention.

The MAMS was shown to deliver clinical outcomes ${ }^{42}$ with low additional costs of intervention. The global cost of providing the service per patient for six months was estimated around $€ 27.5$ ( $€ 4.55$ per patient per month). In the literature reviewed, the intervention cost varies greatly between studies, due to the differences in the intervention schedule (number and type of consultations, training and materials provided, participating agents, duration of the program, etc.), the different methods and units for calculation and country. The intervention cost of the service estimated used in our study is in the lower range between $€ 25$ - $€ 100$, compared to other programs. ${ }^{32,34,35,37,68}$ Other studies have obtained higher intervention costs, due to more complex and longer interventions ${ }^{39}$ or by setting a fixed fee of $£ 51.50$ for the pharmacist irrespective of the time involved. ${ }^{70}$ Therefore, even though our program opted for an intensive intervention (that is, monthly faceto-face interviews) in order to establish and monitor changes in adherence behavior in patients, it has resulted in an intervention cost which is lower than that described in other studies.

The pharmacist's time costs constituted the highest proportion of costs, $91.2 \%$, with $8.8 \%$ spent on costs related to the structure of the pharmacy, initial training and support by the practice change facilitators. As in many health services in primary care, the major investment should be directed to staff time. On average, the pharmacist devoted approximately 20 minutes per patient per monthly visit to service delivery, similar or a bit lower compared to the mean consultation times found in other studies, of $38 \mathrm{~min}^{68}$ or a mean of $26 \mathrm{~min}$ for the initial interview and 14 min for the follow-up interview. ${ }^{34}$ Brief complex interventions, ${ }^{72}$ due to their brevity, may facilitate pharmacists to incorporate an adherence service as part of their existing workflows.

In real-world practice, this intervention time and therefore the major cost, for service delivery would be expected to diminish with the accumulated experience and the repetitive practice of the intervention. MAMS is a service that, due to its methodological characteristics and the nature of interventions, based on behavior change models, follows a learning curve, that is, the more times it is practiced by the pharmacist, the better the provision of the MAMS may work. Learning curves are specifically studied in healthcare education and professions where resources are limited. ${ }^{73-76}$ Applied to our intervention, it means that to lower the cost of the new service, it should increase experience and practice of pharmacists, obtaining better effects after a repetition practice to complete a learning curve. Tersalvi et $\mathrm{al}^{77}$ reported similar effects. In addition, a learning synergy may occur in pharmacists who are already providing other different but related services in their pharmacy. ${ }^{78}$

Despite the costs associated with the use of medication and healthcare resources not differing significantly between study groups, MAMS had a significant positive effect on health-related quality of life of patients. During the study, in the intra-group comparison, the HR-QOL 
increased in both groups of patients. In the case of the control group, it may be due to the increase contact between pharmacist and patient (Hawthorne effect). However, patients in the intervention group experienced almost double the increase of the control group by the end of the study. This is higher than that found in other studies after 12 months of intervention. ${ }^{39,69}$ In the intergroup comparison, a significant difference was observed after the third month. There was also a tendency to increase as the study progressed, similarly to that reported by other authors, ${ }^{35}$ although this effect did not become significantly different until the sixth month. MAMS seems to add to well-being and perceived health of the population and that could be due not only to the impact of adherence but to the complexity and components of the pharmacist-patient interaction that used different models of behavior change.

In the two cost-utility sub-analyses performed, the incremental cost-utility ratio obtained showed that MAMS would be located between the north-east and south-east quadrants of the cost-utility plane. It is interesting that the literature reports conflicting results of the economic impact of adherence interventions with some studies $35,38,68,69$ reporting a dominant ICUR and others ${ }^{39}$ which reported an ICUR higher than in our study, although this particular program included a more complex intervention on the management of medications. These differences are difficult to interpret but could be due to the use of different interventions, research design and methodologies used.

Finally, in this study, considering a cost-effectiveness threshold in Spain of $€ 20,000 / Q A L Y$, the probability of MAMS being cost-effective was $99 \%$. Similar results have been obtained in other programs, with values of $89 \%,{ }^{38}$ $95 \%{ }^{69}$ and $97 \%{ }^{39}$ of probability of being cost-effective, while the economic evaluation of the CATI program ${ }^{32}$ obtained a higher ICUR and a 0.36 probability of being cost-effective with a willingness to pay of $€ 20,000 / \mathrm{QALY}$.

Although not evaluated in this study, the longer term improved clinical control and management, with the resultant economic benefits, are to be expected. However, since the evidence suggests that adherence is a dynamic process and is subject to change these benefits would be dependent on the continued reinforcement of adherence. Over time, an increased ability in efficacy and efficiency of the pharmacists to deliver the intervention would also be expected, which in turn may have a greater impact on adherence rates with a potential to reduce the time to deliver the intervention which was a critical cost in the cost-effectiveness analysis.

\section{Limitations and Strengths}

A health system perspective was chosen since the main direct healthcare costs, such as medication, visits to physicians and hospitalizations could be robustly collected. However, to use a societal perspective would have been challenging to include with our research design and thus is a limitation. Also, data related to treatment dosages and utilization of healthcare resources were obtained from the patient's self-report, although this methodology is used in other studies. ${ }^{34}$ The length of the study may not have allowed the effects of adherence on other variables such as the use of medications or use of healthcare resources to be observed. In contrast, the methodological characteristics and human resources allowed to recruit a large sample of patients. Additionally, the professional skills of the pharmacists who participated and the essential role of the practice change facilitator has been decisive to rigorously measure the fidelity of the intervention.

\section{Conclusion}

The Medication Adherence Management Service, according to the cost-utility analysis performed, was shown to be a cost-effective service, with an incremental cost-utility ratio of $€ 1,433.73 / \mathrm{QALY}$ in the base case analysis and $€ 2,086.30$ /QALY in the complete case analysis, with potential positive gains in HRQoL, that was significantly increased with the pharmacist-led intervention. Longer term studies may be needed as it is suspected that the true gains from patients adhering to their medications may take longer than six to twelve months to have an impact on issues such as control of diseases, hospitalizations rates and use of other healthcare resources. Similarly, costs of intervention may reduce as pharmacists gain greater experience with the service.

The study highlighted the role of the community pharmacist in addressing adherence and health behavior change in patients about medication use, without overlapping the roles and responsibilities of other healthcare professionals. Community pharmacies-led MAMS may be considered as a valuable service to be integrated in primary care.

\section{Acknowledgments}

This publication is part of a doctoral thesis "Evaluation of the impact and implementation of a medication adherence management service from the community pharmacy" developed by María-Isabel Valverde-Merino, of the 
Doctoral Program in Clinical Medicine and Public Health at the University of Granada, Spain.

The authors would like to acknowledge the participation of the practice change facilitators, as well as the provider pharmacists for their contribution to the study.

\section{Funding}

The AdherenciaMED project was supported by the General Pharmaceutical Council of Spain through funds provided by Cinfa Laboratories. The sponsor did not have any role in the design, methods, protocol of the study, data collection and analysis. The provider pharmacists did not receive any remuneration for their participation in the study.

\section{Disclosure}

The authors report no conflicts of interest in this work.

\section{References}

1. Mair A, Wilson M, Dreischulte T. Addressing the challenge of polypharmacy. Annu Rev Pharmacol Toxicol. 2020;60(1):661-681. doi:10.1146/annurev-pharmtox-010919-023508

2. Sabaté E. Adherence to Long-Term Therapies: Evidence for Action. World Health Organization; 2003.

3. Blaschke TF, Osterberg L, Vrijens B, Urquhart J. Adherence to medications: insights arising from studies on the unreliable link between prescribed and actual drug dosing histories. Annu Rev Pharmacol Toxicol. 2012;52(1):275-301. doi:10.1146/annurev-pharmtox-011711-113247

4. Khan R, Socha-Dietrich K. Investing in medication adherence improves health outcomes and health system efficiency: Adherence to medicines for diabetes, hypertension, and hyperlipidaemia. OECD Health Working Papers, No. 105, 2018; OECD Publishing, Paris. doi:10.1787/8178962c-en

5. Senior International Health Association - SIHA. European charter on adherence to therapy; 2016. Available from: https://www.seniorinternatio nalhealthassociation.org/wp-content/uploads/2016/11/European-Charteron-Adherence-to-Therapy-web.pdf. Accessed October 9, 2021.

6. Cutler RL, Fernandez-Llimos F, Frommer M, Benrimoj C, GarciaCardenas V. Economic impact of medication non-adherence by disease groups: a systematic review. BMJ Open. 2018;8(1):e016982. doi:10.1136/bmjopen-2017-016982

7. Vrijens B, Antoniou S, Burnier M, de la Sierra A, Volpe M. Current situation of medication adherence in hypertension. Front Pharmacol. 2017;8:100. doi:10.3389/fphar.2017.00100

8. Mes MA, Katzer CB, Chan AHY, Wileman V, Taylor SJC, Horne R. Pharmacists and medication adherence in asthma: a systematic review and meta-analysis. Eur Respir J. 2018;52(2):1800485. doi:10.1183/13993003.00485-2018

9. Mueller S, Wilke T, Bechtel B, Punekar YS, Mitzner K, Virchow JC. Non-persistence and non-adherence to long-acting COPD medication therapy: a retrospective cohort study based on a large German claims dataset. Respir Med. 2017;122:1-11. doi:10.1016/j.rmed.2016.11.008

10. Mennini FS, Marcellusi A, von der Schulenburg JM, et al. Cost of poor adherence to anti-hypertensive therapy in five European countries. Eur $J$ Health Econ. 2015;16(1):65-72. doi:10.1007/s10198-013-0554-4

11. Kirkland EB, Heincelman M, Bishu KG, et al. Trends in healthcare expenditures among US adults with hypertension: national estimates, 2003-2014. J Am Heart Assoc. 2018;7(11):e008731. doi:10.1161/ JAHA.118.008731.
12. Global Initiative for Asthma (GINA). Global strategy for asthma management and prevention; 2020. Online Appendix. Available from: https://ginasthma.org/reports/ . Accessed October 9, 2021P

13. European Respiratory Society. European lung white book. Chapter 2. The economic burden of lung disease. Available from: https://www. erswhitebook.org/chapters/the-economic-burden-of-lung-disease/. Accessed October 6, 2021.

14. Global Initiative for Chronic Obstructive Lung Disease (GOLD). Global strategy for the diagnosis, management and prevention of chronic obstructive pulmonary disease (2020 report); 2020. Available from: https://goldcopd.org/wp-content/uploads/2019/12/GOLD-2020FINAL-ver1.2-03Dec19_WMV.pdf. Accessed October 9, 2021

15. Wiecek E, Tonin FS, Torres-Robles A, Benrimoj SI, FernandezLlimos F, Garcia-Cardenas V. Temporal effectiveness of interventions to improve medication adherence: a network meta-analysis. PLoS One. 2019;14(3): $\mathrm{e} 213432$. doi:10.1371/journal.pone.0213432

16. Anderson LJ, Nuckols TK, Coles C, et al. A systematic overview of systematic reviews evaluating medication adherence interventions. $\mathrm{Am} \mathrm{J}$ Health Syst Pharm. 2020;77(2):138-147. doi:10.1093/ajhp/zxz284

17. Simon-Tuval T, Neumann PJ, Greenberg D. Cost-effectiveness of adherence-enhancing interventions: a systematic review. Expert Rev Pharmacoecon Outcomes Res. 2016;16(1):67-84. doi:10.1586/ 14737167.2016.1138858

18. Cross AJ, Elliott RA, Petrie K, Kuruvilla L, George J. Interventions for improving medication-taking ability and adherence in older adults prescribed multiple medications. Cochrane Database Syst Rev. 2020; (5). doi:10.1002/14651858.CD012419.pub2

19. Marcum ZA, Hanlon JT, Murray MD. Improving medication adherence and health outcomes in older adults: an evidence-based review of randomized controlled trials. Drugs Aging. 2017;34(3):191-201. doi:10.1007/s40266-016-0433-7

20. Conn VS, Ruppar TM. Medication adherence outcomes of 771 intervention trials: systematic review and meta-analysis. Prev Med. 2017;99:269-276. doi:10.1016/j.ypmed.2017.03.008

21. Milosavljevic A, Aspden T, Harrison J. Community pharmacist-led interventions and their impact on patients' medication adherence and other health outcomes: a systematic review. Int $J$ Pharm Pract. 2018;26(5):387-397. doi:10.1111/ijpp.12462

22. Omboni S, Caserini M. Effectiveness of pharmacist's intervention in the management of cardiovascular diseases. Open Heart. 2018;5(1): e000687. doi:10.1136/openhrt-2017-000687

23. Readdean KC, Heuer AJ, Scott Parrott J. Effect of pharmacist intervention on improving antidepressant medication adherence and depression symptomology: a systematic review and meta-analysis. Res Social Adm Pharm. 2018;14(4):321-331. doi:10.1016/j.sapharm.2017.05.008

24. Dokbua S, Dilokthornsakul P, Chaiyakunapruk N, Saini B, Krass I, Dhippayom T. Effects of an asthma self-management support service provided by community pharmacists: a systematic review and metaanalysis. J Manag Care Spec Pharm. 2018;24(11):1184-1196. doi:10.18553/jmcp.2018.24.11.1184

25. International Pharmaceutical Federation (FIP). Use of Medicines by the Elderly: The Role of Pharmacy in Promoting Adherence. The Hague: International Pharmaceutical Federation; 2018.

26. Doggrell SA. A review of interventions $\geq 6$ months by pharmacists on adherence to medicines in cardiovascular disease: characteristics of what works and what doesn't. Res Social Adm Pharm. 2019;15 (2):119-129. doi:10.1016/j.sapharm.2018.04.003

27. Presley B, Groot W, Pavlova M. Pharmacy-led interventions to improve medication adherence among adults with diabetes: a systematic review and meta-analysis. Res Social Adm Pharm. 2019;15 (9):1057-1067. doi:10.1016/j.sapharm.2018.09.021

28. Newman TV, San-Juan-Rodriguez A, Parekh N, et al. Impact of community pharmacist-led interventions in chronic disease management on clinical, utilization, and economic outcomes: an umbrella review. Res Social Adm Pharm. 2020;16(9):1155-1165. doi:10.1016/ j.sapharm.2019.12.016 
29. Jia X, Zhou S, Luo D, Zhao X, Zhou Y, Cui Y. Effect of pharmacistled interventions on medication adherence and inhalation technique in adult patients with asthma or COPD: a systematic review and meta-analysis. J Clin Pharm Ther. 2020;45(5):1-14.

30. Lelubre M, Kamal S, Genre N, et al. Interdisciplinary medication adherence program: the example of a University Community Pharmacy in Switzerland. Biomed Res Int. 2015;2015:103546. doi:10.1155/2015/103546

31. Van der laan DM, Elders PJM, Boons CCLM, Nijpels G, Dijk L, Hugtenburg JG. Effectiveness of a patient-tailored, pharmacist-led intervention program to enhance Adherence to antihypertensive medication: the CATI study. Front Pharmacol. 2018;9:1057. doi:10.3389/ fphar.2018.01057

32. Bosmans JE, van der Laan DM, Yang Y, et al. The cost-effectiveness of an intervention program to enhance adherence to antihypertensive medication in comparison with usual care in community pharmacies. Front Pharmacol. 2019;10:210. doi:10.3389/fphar.2019.00210

33. van Boven JFM, Stuurman-Bieze AGG, Hiddink EG, Postma MJ, Vegter S. Medication monitoring and optimization: a targeted pharmacist program for effective and cost-effective improvement of chronic therapy adherence. J Manag Care Pharm. 2014;20(8):786792. doi:10.18553/jmcp.2014.20.8.786

34. van Boven JF, Stuurman-Bieze AG, Hiddink EG, Postma MJ. Effects of targeting disease and medication management interventions towards patients with COPD. Curr Med Res Opin. 2016;32(2):229239. doi:10.1185/03007995.2015.1110129

35. Manfrin A, Tinelli M, Thomas T, Krska J. A cluster randomised control trial to evaluate the effectiveness and cost-effectiveness of the Italian medicines use review (I-MUR) for asthma patients. $B M C$ Health Serv Res. 2017;17(1):300. doi:10.1186/s12913-017-2245-9

36. Elliott RA, Boyd MJ, Salema NE, et al. Supporting adherence for people starting a new medication for a long-term condition through community pharmacies: a pragmatic randomised controlled trial of the New Medicine Service. BMJ Qual Saf. 2016;25(10):747-758. doi:10.1136/bmjqs-2015-004400

37. Elliott RA, Boyd MJ, Tanajewski L, et al. "New Medicine Service": supporting adherence in people starting a new medication for a longterm condition: 26-week follow-up of a pragmatic randomised controlled trial. BMJ Qual Saf. 2020;29(4):286-295. doi:10.1136/bmjqs-2018009177

38. Twigg MJ, Wright D, Barton G, Kirkdale CL, Thornley T. The pharmacy care plan service: evaluation and estimate of cost-effectiveness. Res Social Adm Pharm. 2019;15(1):84-92. doi:10.1016/j. sapharm.2018.03.062

39. Foro de Atención Farmacéutica en Farmacia Comunitaria [Forum of Pharmaceutical Care in Community Pharmacy]. Guía práctica para los Servicios Profesionales Farmacéuticos Asistenciales en la Farmacia Comunitaria [A Practical Guide to Professional Pharmaceutical Care Services in Community Pharmacy]. Madrid: Consejo General de Colegios Oficiales de Farmacéuticos; 2019.

40. Martinez-Martinez F. Informe global 2019 adherenciaMED: diseño, evaluación del impacto e implantación de un servicio profesional de adherencia terapéutica desde el ámbito de la farmacia comunitaria [2019 AdherenciaMED global report: design, impact evaluation and implementation of a professional medication adherence service from community pharmacy setting]. Madrid: Consejo General de Colegios Oficiales de Farmacéuticos; 2019.

41. Torres-Robles A, Benrimoj SI, Gastelurrutia MA, et al. Effectiveness of a medication adherence management intervention in a community pharmacy setting: a cluster randomised controlled trial. BMJ Qual Saf. 2021:bmjqs-2020-011671. doi:10.1136/bmjqs-2020-011671

42. Husereau D, Drummond M, Petrou S, et al. Consolidated Health Economic Evaluation Reporting Standards (CHEERS) - explanation and elaboration: a report of the ISPOR health economic evaluation publication guidelines good reporting practices task force. Value Health. 2013;16(2):231-250. doi:10.1016/j.jval.2013.02.002
43. Instituto Nacional de Estadística [National Statistics Institute]. Cálculo de variaciones del indice de precios de consumo (sistema IPC base 2016) [Calculation of the Consumer Price Index percentage changes (CPI system base 2016)]. Available from: https://www.ine.es/varipc/index.do. Accessed October 6, 2021.

44. Pérez-Escamilla B, García-Cárdenas V, Gastelurrutia M, et al. Percepción de los formadores colegiales sobre el futuro profesional de esta nueva figura laboral en la farmacia comunitaria [Perception of Practice Change Facilitators on the professional future of this new job in community pharmacy]. Pharm Care Espana. 2014;16(3):81-88.

45. Cranley LA, Cummings GG, Profetto-McGrath J, Toth F, Estabrooks CA. Facilitation roles and characteristics associated with research use by healthcare professionals: a scoping review. BMJ Open. 2017;7(8): e014384. doi:10.1136/bmjopen-2016-014384

46. Albers B, Metz A, Burke K. Implementation support practitioners - A proposal for consolidating a diverse evidence base. BMC Health Serv Res. 2020;20(1):368. doi:10.1186/s12913-020-05145-1

47. WHO Collaborating Centre for Drug Statistics Methodology. Anatomical, therapeutic, chemical. Structure and principles; February 15, 2018. Available from: https://www.whocc.no/atc/struc ture_and_principles/. Accessed October 6, 2021.

48. Base de Datos de Medicamentos - BotPlus 2.0. General pharmaceutical council of Spain. Available from: https://botplusweb.portal farma.com/. Accessed April 30, 2018.

49. Spanish General Access Point. Autonomous Communities [Comunidades autónomas] - Organization of the Spanish state. Administracion.gob.es; 2021. Available from: https://administracion.gob.es/pag_Home/en/ espanaAdmon/comoSeOrganizaEstado/ComunidadesAutonomas.html\#. YCEAk_mCHIV. Accessed February 8, 2021.

50. Boletín Oficial de Castilla y León. Decreto 83/2013, de 26 de diciembre, por el que se actualizan los precios públicos de la Comunidad de Castilla y León y la tasa por actuaciones administrativas relativas a actividades agrícolas; [Official Gazette of Castilla y León. Decree 83/2013, of December 26, which updates the public prices of the Community of Castilla y León and the fee for administrative actions related to agricultural activities]. 2013. Available from: http://bocyl.jcyl.es $/ \mathrm{html} / 2013 / 12 / 30 / \mathrm{html} /$ BOCYL-D-30122013-6.do. Accessed October 6, 2021.

51. Diario Oficial de Castilla La Mancha. Orden de 17/11/2014, de la Consejería de Sanidad y Asuntos Sociales, por la que se establecen los precios públicos de la asistencia sanitaria y de los servicios prestados en la red de centros sanitarios dependientes del Servicio de Salud de Castilla-La Mancha; [Official Gazette of Castilla La Mancha. Order of 17/11/2014, of the Regional Ministry of Health and Social Affairs, establishing the public prices for healthcare and services provided in the network of healthcare centers dependent on the Castilla-La Mancha Health Service]. 2014. Available from: https://docm.jccm.es/portaldocm/descargarArchivo.do?ruta=2014/11/21/ pdf/2014_15022.pdf\&tipo=rutaDocm. Accessed October 6, 2021.

52. Diario Oficial de Galicia. Decreto 56/2014, de 30 de abril, por el que se establecen las tarifas de los servicios sanitarios prestados en los centros dependientes del Servicio Gallego de Salud y en las fundaciones públicas sanitarias; [Official Gazette of Galicia. Decree 56/2014, of April 30, establishing the rates for health services provided in the centers dependent on the Galician Health Service and in the public health foundations]. 2014. Available from: https://www.xunta.gal/dog/Publicados/2014/20140521/ AnuncioC3K1-140514-0001_es.html. Accessed October 6, 2021.

53. Boletín Oficial de Canarias. Resolución de 29 de marzo de 2017, del Director, por la que se modifica la cuantía de los precios públicos de servicios sanitarios previstos en el Decreto 81/2009, de 16 de junio, por el que se establecen los precios públicos de los servicios sanitarios prestados por el Servicio Canario de la Salud y se fijan sus cuantías [Official Gazette of the Canary Islands. Resolution of March 29, 2017, of the Director, modifying the amount of the public prices of health services provided for in Decree 81/2009, of June 16, by which the public prices of the healthcare services provided by the Canary Health Service are established and their amounts are set.]; 2017. Avaiblable from: http://www.gobiernodecanarias.org/boc/2017/067/002.html. Accessed October 14, 2021. 
54. Ministerio de Sanidad CyBS. Costes hospitalarios, resultados estadísticos anuales, año 2017. Resultados según la versión 32 de los APR-GRD. Pesos y coste hospitalarios para cada nivel de severidad y por GRD basal [Ministry of Health CyBS. Hospital costs, annual statistical results, year 2017. Results according to version 32 of the APR-GRD. Hospital weights and cost for each severity level and by baseline GRD]; 2017. Available from: https://www.mscbs. gob.es/estadEstudios/estadisticas/inforRecopilaciones/ anaDesarrolloGDR.htm. Accessed October 6, 2021.

55. Boletin Oficial del Estado. Resolución de 9 de abril de 2014, de la dirección general de empleo, por la que se registra y publica el laudo arbitral para oficinas de farmacia [Official State Gazette. Resolution of April 9, 2014, of the Directorate General of Employment, which registers and publishes the arbitration award for pharmacy offices]; 2014. Available from: https://www.boe.es/eli/es/res/2014/04/09/(5). Accessed October 14, 21

56. Noain A, Garcia-Cardenas V, Gastelurrutia MA, et al. Cost analysis for the implementation of a medication review with follow-up service in Spain. Int J Clin Pharm. 2017;39(4):750-758. doi:10.1007/ s11096-017-0454-2

57. Badia X, Roset M, Montserrat S, Herdman M, Segura A. [The Spanish version of EuroQol: a description and its applications. European quality of life scale]. Med Clin. 1999;112(Suppl 1):7985. Spanish.

58. Ramos-Goñi JM, Pinto-Prades JL, Oppe M, Cabasés JM, SerranoAguilar P, Rivero-Arias O. Valuation and modeling of EQ-5D-5L health states using a hybrid approach. Med Care. 2017;55(7):e51e58. doi:10.1097/MLR.0000000000000283

59. Drummond MF, O'brien BJ, Stoddart GL, Torrance GW. Métodos Para La Evaluación Económica De Los Programas De Asistencia Sanitaria[Methods for the Economic Evaluation of Health Care Programmes]. Ediciones Díaz de santos; 2001.

60. Faria R, Gomes M, Epstein D, White IR. A guide to handling missing data in cost-effectiveness analysis conducted within randomised controlled trials. Pharmacoeconomics. 2014;32(12):1157-1170. doi:10.1007/s40273-014-0193-3

61. O'Brien BJ, Briggs AH. Analysis of uncertainty in health care costeffectiveness studies: an introduction to statistical issues and methods. Stat Methods Med Res. 2002;11(6):455-468. doi:10.1191/ 0962280202sm304ra

62. Vallejo-Torres L, García-Lorenzo B, Serrano-Aguilar P. Estimating a cost-effectiveness threshold for the Spanish NHS. Health Econ. 2018;27(4):746-761. doi:10.1002/hec.3633

63. Gastelurrutia MA, Faus MJ, Martínez-Martínez F. Primary health care policy and vision for community pharmacy and pharmacists in Spain. Pharm Pract. 2020;18(2). doi:10.18549/pharmpract.2020.2.1999

64. Pharmaceutical Services Negotiating Committee. The value of community pharmacy - summary report; 2016. Available from: https:// psnc.org.uk/wp-content/uploads/2016/09/The-value-of-communitypharmacy-summary-report.pdf. Accessed June 28, 2021.

65. Gagnon-Arpin IDA, Sutherland G, Stonebridge C, Dinh T. The value of expanded pharmacy services in Canada; 2017. Available from: https://pans.ns.ca/system/files/files/page/8721_expanded_pharmacy_ rpt_embargoed.pdf. Accessed October 14, 20

Patient Preference and Adherence

\section{Publish your work in this journal}

Patient Preference and Adherence is an international, peer-reviewed, open access journal that focusing on the growing importance of patient preference and adherence throughout the therapeutic continuum. Patient satisfaction, acceptability, quality of life, compliance, persistence and their role in developing new therapeutic modalities and compounds to optimize clinical outcomes for existing disease
66. Pharmaceutical Group of the European Union (PGEU). PHARMACY 2030: A Vision for Community Pharmacy in Europe; 2019. Available from: https://www.pgeu.eu/publications/pharmacy-2030-a-vision-forcommunity-pharmacy-in-europe/. Accessed October 14, 2021

67. van Boven JF, Tommelein E, Boussery K, et al. Improving inhaler adherence in patients with chronic obstructive pulmonary disease: a cost-effectiveness analysis. Respir Res. 2014;15(1):66. doi:10.1186/ 1465-9921-15-66

68. Khdour MR, Agus AM, Kidney JC, Smyth BM, McElnay JC, Crealey GE. Cost-utility analysis of a pharmacy-led self-management programme for patients with COPD. Int J Clin Pharm. 2011;33 (4):665-673. doi:10.1007/s11096-011-9524-z

69. Desborough JA, Sach T, Bhattacharya D, Holland RC, Wright DJ. A cost-consequences analysis of an adherence focused pharmacist-led medication review service. Int $J$ Pharm Pract. 2012;20(1):41-49. doi:10.1111/j.2042-7174.2011.00161.x

70. Elliott RA, Tanajewski L, Gkountouras G, et al. Cost effectiveness of support for people starting a new medication for a long-term condition through community pharmacies: an economic evaluation of the New Medicine Service (NMS) Compared with Normal Practice. Pharmacoeconomics. 2017;35(12):1237-1255. doi:10.1007/s40273017-0554-9

71. Pringle JL, Boyer A, Conklin MH, McCullough JW, Aldridge A. The Pennsylvania project: pharmacist intervention improved medication adherence and reduced health care costs. Health Aff. 2014;33 (8):1444-1452. doi:10.1377/hlthaff.2013.1398

72. Nieuwlaat R, Wilczynski N, Navarro $\mathrm{T}$, et al. Interventions for enhancing medication adherence. Cochrane Database Syst Rev. 2014;(11):Cd000011. doi:10.1002/14651858.CD000011.pub4

73. Waldman JD, Yourstone SA, Smith HL. Learning curves in health care. Health Care Manag Rev. 2003;28(1):41-54. doi:10.1097/ 00004010-200301000-00006

74. Pusic MV, Boutis K, Hatala R, Cook DA. Learning curves in health professions education. Acad Med. 2015;90(8):1034-1042. doi:10.1097/ACM.0000000000000681

75. Howard NM, Cook DA, Hatala R, Pusic MV. Learning curves in health Professions education simulation research: a systematic review. Simulat Healthc. 2021;16(2):128-135. doi:10.1097/ SIH.0000000000000477

76. Duncan EM, Francis JJ, Johnston M, et al. Learning curves, taking instructions, and patient safety: using a theoretical domains framework in an interview study to investigate prescribing errors among trainee doctors. Implement Sci. 2012;7(1):86. doi:10.1186/17485908-7-86

77. Tersalvi G, Vicenzi M, Kirsch K, et al. Structured telephone support programs in chronic heart failure may be affected by a learning curve. J Cardiovas Med. 2020;21(3):231-237. doi:10.2459/ JCM.0000000000000934

78. Schilling MA, Vidal P, Ployhart RE, Marangoni A. Learning by doing something else: variation, relatedness, and the learning curve. Manage Sci. 2003;49(1):39-56. doi:10.1287/mnsc.49.1.39.12750

states are major areas of interest for the journal. This journal has been accepted for indexing on PubMed Central. The manuscript management system is completely online and includes a very quick and fair peer-review system, which is all easy to use. Visit http:// www.dovepress.com/testimonials.php to read real quotes from published authors. 